\title{
Serum High-Sensitive C-reactive Protein May Reflect Periodontitis in Patients With Stroke
}

\author{
HANNA TUOMINEN ${ }^{1 *}$, MIKKO TAINA $^{2,3 *}$, MIRJA PURANEN $^{4,5}$, \\ JUHA ONATSU ${ }^{6}$, SISKO HUUMONEN ${ }^{1,3}$ and RITVA VANNINEN ${ }^{2,3}$ \\ ${ }^{1}$ The Institute of Dentistry, University of Eastern Finland, Kuopio, Finland; \\ ${ }^{2}$ Unit of Radiology, Institute of Clinical Medicine, University of Eastern Finland, Kuopio, Finland; \\ ${ }^{3}$ Department of Clinical Radiology, Kuopio University Hospital, Kuopio, Finland; \\ ${ }^{4}$ Department of Pathology, Kuopio University Hospital, Kuopio, Finland; \\ ${ }^{5}$ Oral and Maxillofacial Department, Kuopio University Hospital, Kuopio, Finland; \\ ${ }^{6}$ NeuroCenter, Kuopio University Hospital, Kuopio, Finland
}

\begin{abstract}
Background/Aim: Chronic infectious diseases are believed to increase the risk of stroke. We aimed to evaluate the prevalence of periodontal disease and its association with systemic inflammatory processes in patients suffering an acute stroke/transient ischemic attack (TIA). Patients and Methods: Altogether 36 acute stroke/TIA patients underwent clinical, laboratory and radiological examinations. The level of systemic inflammation was analyzed both with routine measurements of plasma $C$-reactive protein ( $p$-CRP) and serum high-sensitivity CRP (s-hsCRP) to analyze their associations with periodontitis. The diagnostic criteria for periodontitis included increased probing depth $(>4 \mathrm{~mm}$ ) measured from four different sites, bleeding on probing, and horizontal (>1 mm), vertical $(>1 \mathrm{~mm})$ or apical bone loss observed on orthopantomography. Results: Twenty-six (72.2\%) patients were diagnosed with periodontitis. Only five of the patients with periodontitis $(19.2 \%)$ had elevated $p$-CRP values whereas the majority, $(17 / 26 ; 65.4 \%)$ had elevated $s$ hsCRP values $(p<0.01)$. Absolute $s$-hsCRP values in patients with periodontitis $(8.9 \pm 12.5 \mathrm{mg} / \mathrm{l})$ were significantly higher than in patients without periodontitis $(2.3 \pm 3.0 \mathrm{mg} / \mathrm{l} ; \mathrm{p}<0.05)$. Absolute p-CRP concentrations did not differ (2.3 $\pm 5.8 \mathrm{vs}$. $2.4 \pm 5.1 \mathrm{mg} / \mathrm{l} ; \mathrm{p}=$ not significant). The total number of
\end{abstract}

This article is freely accessible online.

*These Authors contributed equally to this study.

Correspondence to: Hanna Tuominen, The Institute of Dentistry, University of Eastern Finland, P.O. Box 1627, FI-70211 Kuopio, Finland. Tel: +358 408392235, Fax +358 17174122, e-mail: hannatai@student.uef.fi

Key Words: Stroke, periodontitis, high-sensitive C-reactive protein. periodontitis findings was significantly associated with $s$-hsCRP values ( $r=1.83)$ but not with $p$-CRP values. Conversely, seventeen of the nineteen patients with elevated $s$-hsCRP (89.5\%) indicative of systemic inflammation had periodontitis. Conclusion: Periodontitis is a common finding among patients with acute stroke/TIA as over $80 \%$ of patients with cryptogenic stroke/TIA had periodontitis. S-hsCRP is a useful tool for detecting subclinical systemic inflammation.

Stroke is the leading cause of long-term disability and stroke patients are a major consumer of health-care resources worldwide (1). Stroke is responsible for $10 \%$ of all deaths and is the second highest cause of mortality $(1,2)$. Cryptogenic strokes account for almost $25 \%$ of ischemic strokes despite modern diagnostic evaluation techniques (2). Periodontal disease is an infectious disease associated with an inadequate localized immunological response. It is characterized by progressive loss of periodontal connective tissue and alveolar bone support and it is a major cause of tooth loss in adults. The symptoms are spontaneous or induced bleeding gums, the formation of gingival pockets and bone loss and finally tooth mobility. The various types of periodontal disease are mainly estimated clinically (bleeding, pocket depth) and radiographically (bone loss) (3). It has been estimated that at least $35 \%$ of adults in the Western population aged 30 years and older have periodontitis (4). The epidemiological link between periodontal disease and cerebral infarction was first revealed in $1989(5,6)$. Periodontitis is related to an increase in systemic inflammation markers through exposure to Gramnegative bacteria $(3,7-9)$, which have also been implicated in the etiology of atherosclerosis and stroke (6).

In addition to stroke patients with large artery atherosclerosis, we hypothesized that periodontal disease would also be common in patients with stroke of unknown 


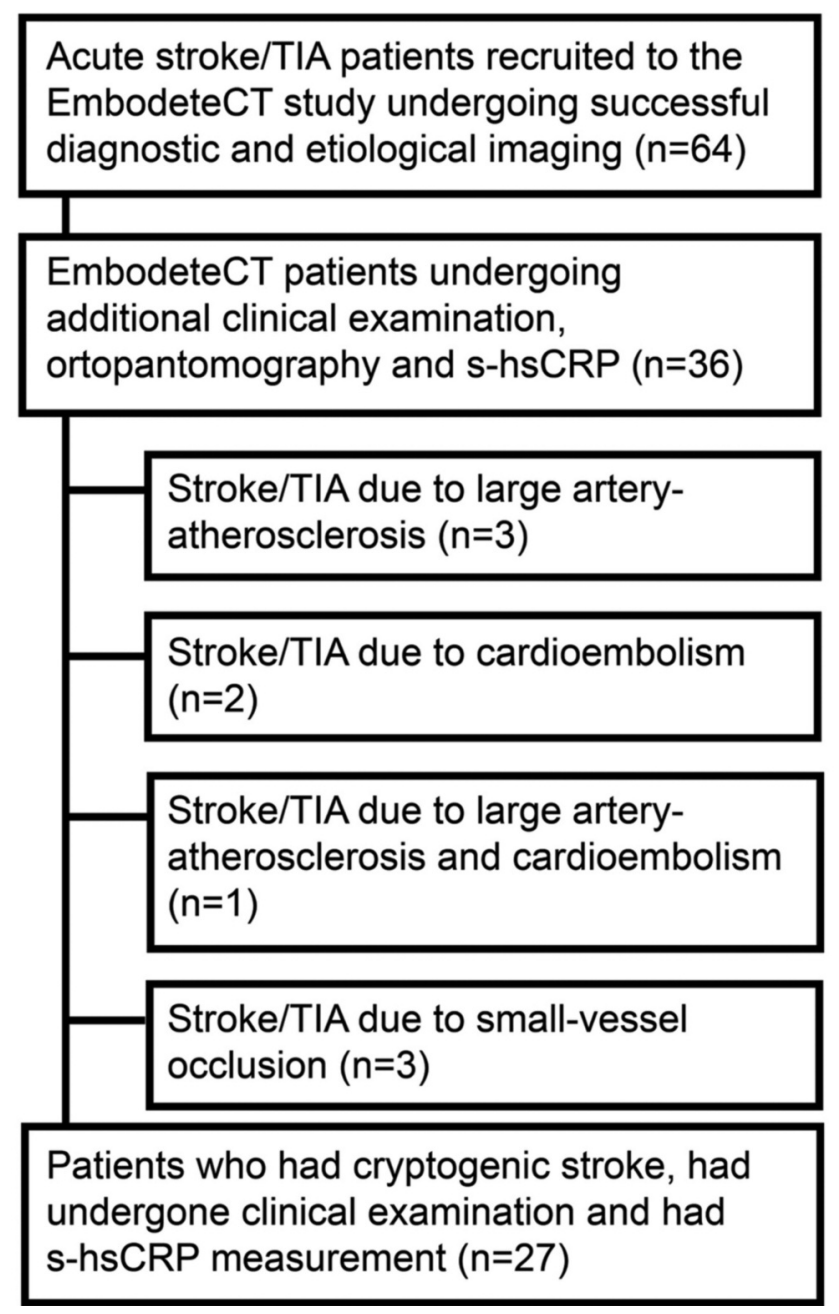

Figure 1. Flow chart of patient recruitment.

origin, i.e. in patients with no signs of atherosclerosis in their cervicocranial arteries and displaying no evidence of cardiogenic stroke.

The purpose of this prospective study was to evaluate the prevalence of periodontal disease in patients with an acute stroke or transient ischemic attack (TIA). The level of subclinical systemic inflammation was analyzed both with measurements of routine plasma $\mathrm{C}$-reactive protein ( $\mathrm{p}-\mathrm{CRP}$ ) and the more robust serum high-sensitivity CRP (s-hsCRP).

\section{Patients and Methods}

The current study was conducted according to the Declaration of Helsinki and the protocol was reviewed and approved by the Kuopio University Hospital Research Ethics Board (No: 82/2004). Prior to participation in the study, written informed consent was obtained from the patient or the patient's legally authorized representative.

This was a prospective single-center observational cohort study nested within EmbodeteCT Study (10). Patients who were admitted
Table I. Clinical characteristics of the included patients.

\begin{tabular}{lc}
\hline & All patients (N=36) \\
\hline Age, years & $59.3 \pm 10.5$ \\
Males, $\mathrm{n}(\%)$ & $27(75.0)$ \\
Body mass index, $\mathrm{kg} / \mathrm{m}^{2}$ & $29.1 \pm 4.3$ \\
Caucasian race, $\mathrm{n}(\%)$ & $36(100)$ \\
Hypertension, $\mathrm{n}(\%)$ & $22(61.1)$ \\
Hyperlipidemia, $\mathrm{n}(\%)$ & $16(44.4)$ \\
Diabetes, $\mathrm{n}(\%)$ & $3(8.3)$ \\
Smokers, $\mathrm{n}(\%)$ & $9(25.0)$ \\
Stroke, $\mathrm{n}(\%)$ & $25(96.4)$ \\
TIA, $\mathrm{n}(\%)$ & $11(30.6)$ \\
Number of teeth, $\mathrm{n}$ & $14.5 \pm 10.9$ \\
Gingival bleeding, $\mathrm{n}(\%)$ & $19(52.8)$ \\
Vertical bone loss, $\mathrm{n}(\%)$ & $6(16.7)$ \\
Horizontal bone loss, $\mathrm{n}(\%)$ & $20(55.6)$ \\
Apical periodontitis, $\mathrm{n}(\%)$ & $6(16.7)$ \\
Deepening of the gingival sulcus, $\mathrm{n}(\%)$ & $13(36.1)$ \\
Periodontitis, $\mathrm{n}(\%)$ & $26(72.2)$ \\
\hline
\end{tabular}

S-hsCRP: Serum high-sensitivity C-reactive protein; TIA: transient ischemic attack.

to our University Hospital during the study period August 2007 to November 2009 due to stroke or TIA with an unknown or suspected cardioembolic etiology, but without known atrial fibrillation (AF), were evaluated as candidates for the study. A total of 64 patients were recruited and underwent the diagnostic and etiological investigations including a combined examination of the brain, heart, aorta, and cervicocranial arteries with computed tomography (CT). Sixteen patients also underwent magnetic resonance imaging of the brain. Stroke/TIA etiology was determined according to the protocol of the clinical trial of ORG 10172 for the treatment of acute stroke with the classification modified by recommendations from the European Association of Echocardiography $(11,12)$ for defining the cardiac source of the embolism (Figure 1).

Patients. Altogether 36 out of 64 patients also underwent clinical examination. The same dentist examined all the patients. The diagnostic criteria for periodontitis included increased probing depth ( $>4 \mathrm{~mm}$ ) measured from four different sites, bleeding on probing, and horizontal $(>1 \mathrm{~mm})$, vertical $(>1 \mathrm{~mm})$ or apical bone loss seen on orthopantomography (OPG). All the OPG images were evaluated by an experienced specialist. If only bleeding on probing was detected without connective tissue loss, a diagnosis of gingivitis was made instead of periodontitis.

The blood serum samples were collected within 1-4 days after stroke onset. Routine blood sample analysis including p-CRP was performed in our University hospital laboratory whereas the analysis of s-hsCRP measurements was performed by the Finnish Red Cross Blood Service. p-CRP was considered elevated when values were over $5 \mathrm{mg} / \mathrm{l}$ and s-hsCRP when over $2.234 \mathrm{mg} / \mathrm{l}$.

Statistical analysis. Continuous variables are presented as means or medians, and categorical variables as absolute counts and percentages. Student's $t$-test was used to compare two normally distributed continuous variables, the Mann-Whitney $U$-test to analyze the two non-normally distributed continuous variables and 

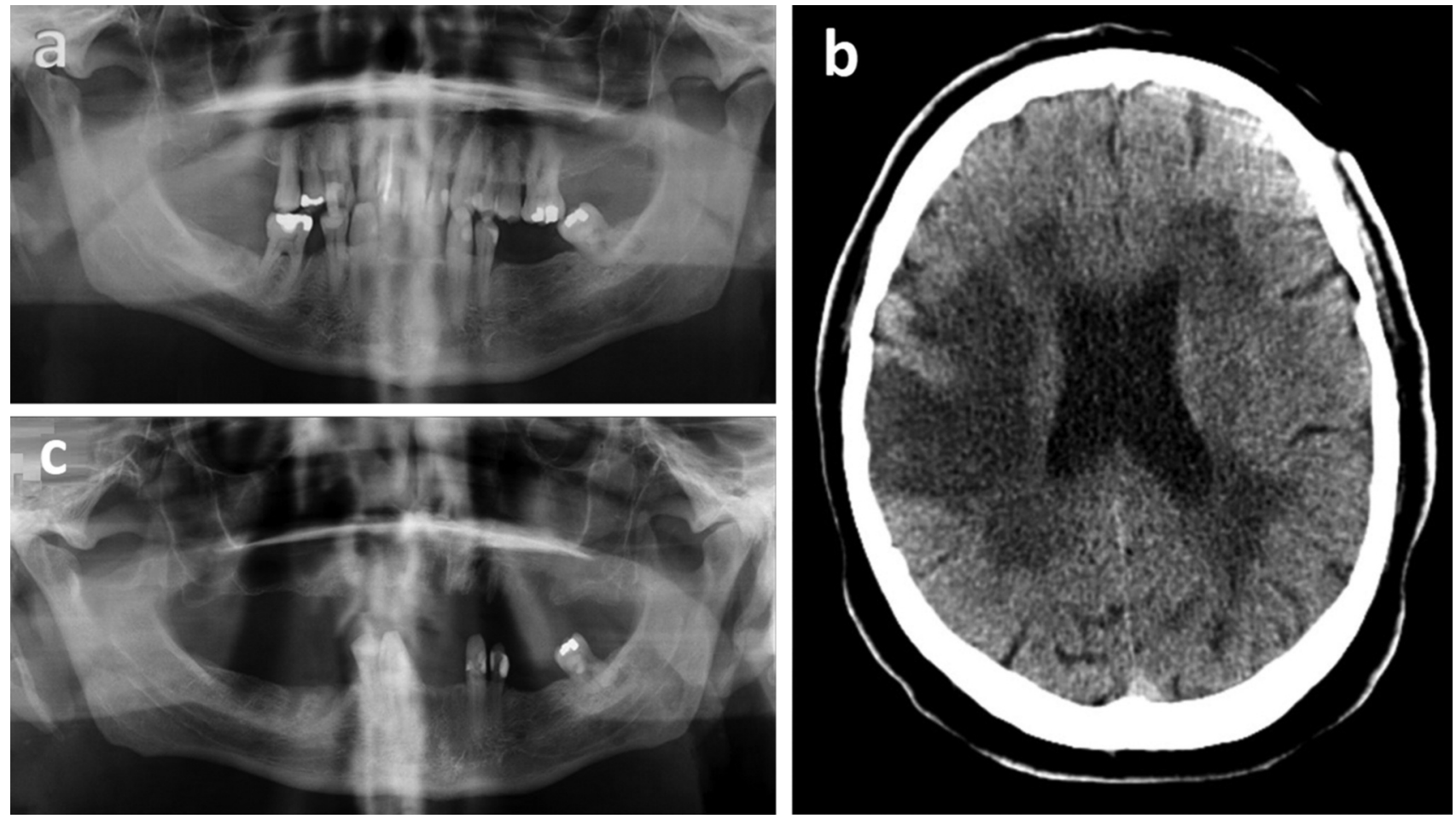

Figure 2. Illustrative images of a sixty-year-old male patient with acute left side hemiparesis. The patient had a long smoking history, hypertension, type II diabetes mellitus, heart failure, hyperlipidemia and chronic atrial fibrillation treated with warfarin medication. (a) Orthopantomogram six years prior to the stroke. Medium to severe horizontal bone loss caused by chronic periodontitis. Bone loss compatible with inflammation in the apical areas of four teeth. (b) In the subacute phase, non-contrast computed tomography revealed a cortical infarction in the middle cerebral artery territory in the right hemisphere. White matter showed evidence of chronic vascular degeneration bilaterally. The P-CRP level was normal; in contrast, the s-hsCRP mean concentration was $36.9 \mathrm{mg} / \mathrm{l}$, being markedly elevated i.e. the reference value is 0.05-2.5 mg/l. (c) Orthopantomogram four months after stroke. Medium to severe horizontal bone loss caused by chronic periodontitis. Bone loss compatible with inflammation in the apical areas of two teeth.

the Kruskal-Wallis test to evaluate multiple non-normally distributed variables. Two-tailed Pearson correlation coefficient and Spearman`s rank correlation coefficient were applied to investigate the association between continuous normally distributed and nonnormally distributed variables, respectively. The Chi-square test with Pearson's or Fisher's correlation was used to compare nominal variables. When assessing the independent association of pCRP and s-hsCRP with the prevalence of periodontitis, we computed multivariate logistic regression models adjusted for established predictors. Stepwise regression models were utilized. Analysis of variance and linear regression models were used to compare shsCRP levels in patients with and without periodontitis. All regression models were adjusted for age. Testing was 2 -sided and $p$-values less than 0.05 were considered to be statistically significant. The data were analyzed using IBB SPSS for Windows, version 19.0 (SPSS Inc., Chicago, IL, USA).

\section{Results}

Table I shows the clinical characteristics of the 36 acute stroke/TIA patients recruited in the study. After intensive etiological examinations, the most frequent etiology for stroke proved to be cryptogenic $(\mathrm{N}=27 ; 75.0 \%)$. Altogether 26 patients $(72.2 \%)$ were diagnosed with periodontitis. The prevalence of the clinical findings is shown in Table I. There were no significant correlations between any background characteristics and periodontitis, p-CRP or s-hsCRP concentrations. Seven patients (19.4\%) had elevated levels of p-CRP (mean=10.9 $\pm 6.4 \mathrm{mg} / \mathrm{l})$ and 29 patients $(80.6 \%)$ had normal (i.e. under $5 \mathrm{mg} / \mathrm{l}$ ) p-CRP values. Nineteen patients $(52.5 \%)$ had elevated s-hsCRP (mean=12.4 $\pm 13.2 \mathrm{mg} / \mathrm{l})$ concentration while 17 patients $(47.2 \%)$ had normal (i.e. under $2,234 \mathrm{mg} / \mathrm{l}$ ) s-hsCRP (mean $1.1 \pm 0.7 \mathrm{mg} / \mathrm{l}$ ) levels.

If we consider the patients with elevated s-hsCRP levels indicative of systemic inflammation, then almost all $(n=17$, $89.5 \%$ ) had periodontitis. Of the patients diagnosed with periodontitis, the majority, $(\mathrm{n}=17)(65.4 \%)$ had elevated shsCRP $(p<0.01)$; while only five $(19.2 \%)$ had elevated $\mathrm{p}$ CRP (Figure 2). Absolute s-hsCRP values in patients with periodontitis $(8.9 \pm 12.5 \mathrm{mg} / \mathrm{l})$ were significantly higher than in patients without periodontitis $(2.3 \pm 3.0 \mathrm{mg} / 1 ; p<0.05)$. Absolute p-CRP values did not differ $(2.3 \pm 5.8$ vs. $2.4 \pm 5.1$ 
Table II. Total number of periodontitis associated with the level of $s$ hsCRP.

\begin{tabular}{lccc}
\hline $\begin{array}{l}\text { Number of periodontitis } \\
\text { findings per patient }\end{array}$ & $\begin{array}{c}\text { Number of } \\
\text { patients }\end{array}$ & $\begin{array}{c}\mathrm{p}-\mathrm{CRP} \\
(\mathrm{mg} / \mathrm{l} ; p=\mathrm{ns})\end{array}$ & $\begin{array}{c}\mathrm{s}-\mathrm{hsCRP} \\
(\mathrm{mg} / \mathrm{l} ; p<0.05)\end{array}$ \\
\hline 0 & 10 & $2.4 \pm 5.1$ & $2.3 \pm 3.0$ \\
1 & 1 & 13.0 & 15.8 \\
2 & 8 & $5.9 \pm 8.6$ & $4.3 \pm 3.2$ \\
3 & 5 & 0.0 & $7.4 \pm 8.9$ \\
4 & 3 & 0.0 & $8.0 \pm 8.5$ \\
5 & 2 & 0.0 & $2.2 \pm 0.28$ \\
6 & 3 & 0.0 & $20.8 \pm 28.8$ \\
7 & 3 & 0.0 & $5.6 \pm 7.7$ \\
8 & 1 & 0.0 & 37.0 \\
\hline
\end{tabular}

p-CRP: Plasma C-reactive protein; s-hsCRP: serum high-sensitivity Creactive protein; ns: not significant.

$\mathrm{mg} / \mathrm{l} ; p=$ not significant). The total number of periodontitis findings was significantly associated with s-hsCRP values ( $r=1.82$ ), but not with p-CRP values (Table II and Figure 3). Due to the small patient number, the multivariate analysis revealed no significant association between pCRP or shsCRP values and periodontitis.

\section{Discussion}

In this study, we found that 26 patients out of 36 recruited stroke/TIA patients had periodontitis. Periodontitis appears to be very common in stroke/TIA patients. Nineteen of our patients had elevated serum hsCRP levels and 17 of these patients had periodontitis. Thus, periodontitis as chronic inflammation seems to be a risk factor for stroke/TIA.

Syrjanen et al. in 1986, first suggested that chronic inflammation, including periodontitis, could be a risk factor for stroke (5). Since then, there have been a number of studies addressing this possibility (13). There are common risk factors between periodontitis and stroke, such as age, smoking, diabetes, hypertension, and cardiovascular disease (14-16). Periodontitis is associated with elevated markers of inflammation that are also indicators of the risk of stroke; however, the epidemiological association between periodontitis and stroke is still controversial.

Chronic infections promote atherosclerosis resulting in subendothelial deposition of cholesterol, cholesterol esters, and calcium within the vessel walls. Unstable atherosclerotic plaques that are prone to rupture have a thin fibrous cap, a large lipid core, and are rich in macrophages (17). Rupture of the atherosclerotic plaques releases debris and thrombi that may travel distally resulting in distal embolization and stroke. Three theories have been proposed to explain the mechanism behind the association between periodontitis and atherosclerotic plaques: 1) The "theory of bacterial invasion" assumes that there is a direct action of bacteria and their toxins on the endothelium $(18) ; 2$ ) "the cytokine theory" postulates that inflammatory mediators released by the cells of the immune system play a key role in the damage to the vascular wall endothelium (19); and 3) "the autoimmunization theory" emphasizes the significance of heat shock proteins expressed by the oral pathogens (20).

Our study highlights the high prevalence of periodontitis in stroke patients who have no significant calcification or atherosclerotic lesions in their supra-aortic arteries or no history of coronary artery disease. This is in line with previous research findings. Lafon et al. stated that the presence of gingivitis exerted no significant effect on the occurrence of stroke (21). Unlike periodontitis, gingivitis is a superficial inflammation of the periodontal tissue without any loss of attachment tissue or bone loss.

Subclinical systemic inflammatory conditions may either reflect the presence of periodontitis or other inflammatory process predisposing the patient to stroke. Because these findings are very common in patients with acute stroke, it is not possible to directly conclude that periodontitis is an independent risk factor for stroke/TIA.

There were 26 patients with periodontitis, but only 7 had elevated p-CRP levels. In general, p-CRP is very sensitive and reacts to various inflammatory conditions within a few hours. Some previous studies have reported an association between periodontitis and $\mathrm{p}$-CRP values $(22,23)$. There are also data showing that CRP is produced locally by the inflamed periodontium and may play some other role in the pathogenesis of periodontal disease. It is not known whether such locally produced extra-hepatic CRP has the potential to modulate systemic circulatory CRP levels (24-26). Our study included $80.8 \%$ patients with periodontitis who had no elevation of plasma CRP. However, $65.4 \%$ patients having periodontitis did not have elevated levels of s-hsCRP. According to our results, s-hsCRP seems to be a useful tool for detecting subclinical systemic inflammation. This finding might be especially relevant in view of a recent report that showed an increased risk of stroke in patients with elevated s-hsCRP levels (27).

It has been estimated that in developed countries, at least $35 \%$ of adults aged 30 years and older have periodontitis; $22 \%$ have a mild form and $13 \%$ have a moderate or severe form (7). In our study, we evaluated periodontitis by the number of patients instead of categorizing severity into three forms. The prevalence of periodontitis is typically assessed in epidemiological studies on the basis of three clinical variables i.e. gingival bleeding sensitivity (bleeding on probing), depth of gingival pockets, and clinical attachment around the root of the tooth. These same criteria were used for the definition of periodontitis in this study, but because the study population was small, no grading of periodontitis severity was performed.

The small study population was the main limitation of the study. The size of our sample dictates the amount of 

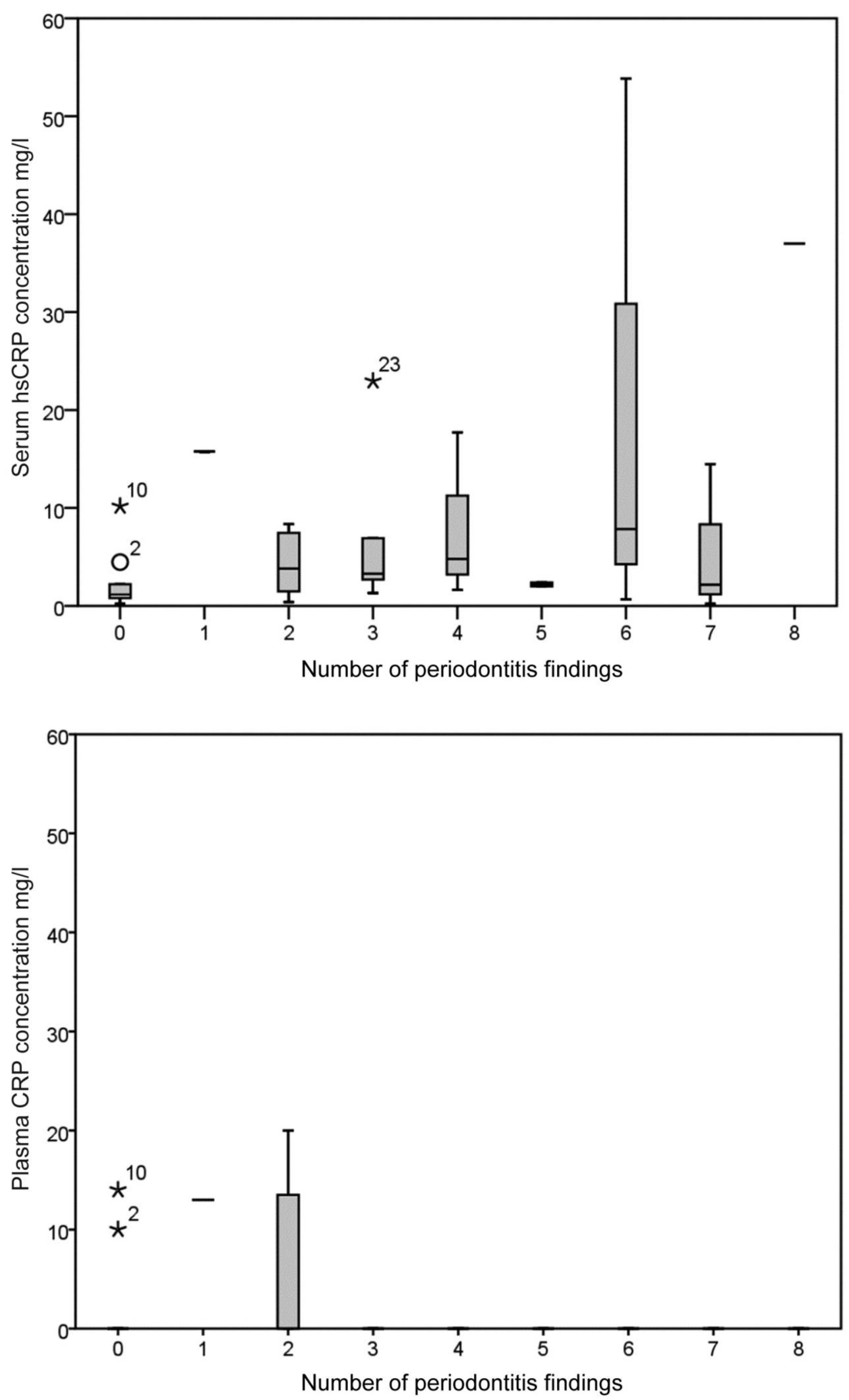

Figure 3. The number of periodontitis findings was significantly associated with the elevated $s$-hsCRP ( $p<0.05$, upper image) values but not with the increase in the p-CRP concentration (lower image). 
information we have and therefore, in part, determines our precision or level of confidence that we have in our sample estimates. An estimate always has an associated level of uncertainty, which depends upon the underlying variability of the data as well as the sample size. The more variable the population, the greater the uncertainty in our estimate. With such a limited patient material, it is impossible to reveal causality between the inflammation process and stroke occurrence. Nonetheless, our study strongly implies that periodontitis is a very common finding among patients with stroke of unknown origin.

\section{Conclusion}

Over $80 \%$ of patients with stroke/TIA had periodontitis. Our results showed that in addition to the previously well recognized associations between periodontitis and atherosclerosis, periodontitis is also a very common finding among patients with stroke of unknown origin. S-hsCRP does seem to provide a more sensitive tool for detecting subclinical inflammation than the more commonly used pCRP. An elevated s-hsCRP level may thus help detect the response to periodontal treatment.

\section{Conflicts of Interest}

The Authors declare that there are no conflicts of interest with regards to present study.

\section{Authors' Contributions}

All Authors listed, have made substantial, direct and intellectual contribution to the work, and approved it for publication.

\section{References}

1 Bonita R: Epidemiology of stroke. Lancet 339(8789): 342-344, 1992. PMID: 1346420. DOI: 10.1016/0140-6736(92)91658-u

2 Murray CJ and Lopez AD: Mortality by cause for eight regions of the world: Global burden of disease study. Lancet 349(9061): 1269-1276, 1997. PMID: 9142060. DOI: 10.1016/S01406736(96)07493-4

3 Pihlstrom BL, Michalowicz BS and Johnson NW: Periodontal diseases. Lancet 366(9499): 1809-1820, 2005. PMID: 16298220. DOI: $10.1016 / \mathrm{S} 0140-6736(05) 67728-8$

4 Albandar JM, Brunelle JA and Kingman A: Destructive periodontal disease in adults 30 years of age and older in the United States, 1988-1994. J Periodontol 70(3): 13-29, 1999. PMID: 10052767. DOI: 10.1902/jop.1999.70.1.13

5 Syrjänen J, Peltola J, Valtonen V, Iivanainen M, Kaste M and Huttunen JK: Dental infections in association with cerebral infarction in young and middle-aged men. J Intern Med 225(3): 179-184, 1989. PMID: 2703800. DOI: 10.1111/j.1365-2796. 1989.tb00060.x

6 Fagundes NCF, Almeida APCPSC, Vilhena KFB, Magno MB, Maia LC and Lima RR: Periodontitis as a risk factor for stroke:
A systematic review and meta-analysis. Vasc Health Risk Manag 15(1): 519-532, 2019. PMID: 31806984. DOI: 10.2147/ VHRM.S204097

7 Mustapha IZ, Debrey S, Oladubu M and Ugarte R: Markers of systemic bacterial exposure in periodontal disease and cardiovascular disease risk: a systematic review and metaanalysis. J Periodontol 78(12): 2289-2302, 2007. PMID: 18052701. DOI: 10.1902/jop.2007.070140

8 Romagna C, Dufour L, Troisgros O, Lorgis L, Richard C, Buffet P, Soulat G, Casillas JM, Rioufol G, Touzery C, Zeller M, Laurent $\mathrm{Y}$ and Cottin Y: Periodontal disease: a new factor associated with the presence of multiple complex coronary lesions. J Clin Periodontol 39(1): 38-44, 2012. PMID: 22092604. DOI: $10.1111 / \mathrm{j} .1600-051 X .2011 .01802 . x$

9 You Z, Cushman M, Jenny NS and Howar, G: Tooth loss, systemic inflammation, and prevalent stroke among participants in the Reasons for Geographic and Racial Difference in Stroke (REGARDS) study. Atherosclerosis 203(2): 615-619, 2009. PMID: 18801482. DOI: 10.1016/j.atherosclerosis.2008.07.037

10 Taina M, Vanninen R, Hedman M, Jäkälä P, Kärkkäinen S, Tapiola $\mathrm{T}$ and Sipola P: Left atrial appendage volume increased in more than half of patients with cryptogenic stroke. PLoS One 8(11): e79519, 2013. PMID: 24223960. DOI: 10.1371/journal. pone. 0079519

11 Adams HP Jr, Bendixen BH, Kappelle LJ, Biller J, Love BB Gordon DL and Marsh EE $3^{\text {rd }}$.: Classification of subtype of acute ischemic stroke. Definitions for use in a multicenter clinical trial. TOAST. Trial of Org 10172 in Acute Stroke Treatment. Stroke 24(1): 35-41, 1993. PMID: 7678184. DOI: 10.1161/01.str.24.1.35

12 Pepi M, Evangelista A, Nihoyannopoulos P, Flachskampf FA, Athanassopoulos G, Colonna P, Habib G, Ringelstein EB, Sicari R, Zamorano JL, Sitges M, Caso P and European Association of Echocardiography: Recommendations for echocardiography use in the diagnosis and management of cardiac sources of embolism: European Association of Echocardiography (EAE) (a registered branch of the ESC). Eur J Echocardiogr 11(6): 461476, 2010. PMID: 20702884. DOI: 10.1093/ejechocard/jeq045

13 Grau AJ1, Becher H, Ziegler CM, Lichy C, Buggle F, Kaiser C, Lutz R, Bültmann S, Preusch M and Dörfer CE: Periodontal disease as a risk factor for ischemic stroke. Stroke 35(2): 496501, 2004. PMID: 14707235. DOI: 10.1161/01.STR.0000110789. 20526.9D

14 Joshipura KJ, Hung HC, Rimm EB, Willett WC and Ascherio A: Periodontal disease, tooth loss, and incidence of ischemic stroke. Stroke 34(1): 47-52, 2003. PMID: 12511749. DOI: 10.1161/ 01.str.0000052974.79428.0c

15 Beck J, Garcia R, Heiss G, Vokonas PS and Offenbacher S: Periodontal disease and cardiovascular disease. J Periodontol 67(10): 1123-1137, 1996. PMID: 8910831. DOI: 10.1902/jop. 1996.67.10s.1123

16 Pradeep AR, Hadge P, Arjun Raju P, Shetty SR, Shareef K and Guruprasad CN: Periodontitis as a risk factor for cerebrovascular accident: a casecontrol study in the Indian population. J Periodontal Res 45(2): 223-228, 2010. PMID: 19778330. DOI: 10.1111/j.1600-0765.2009.01220.x

17 Davies MJ, Richardson PD, Woolf N, Katz DR and Mann J: Risk of thrombosis in human atherosclerotic plaques: role of extracellular lipid, macrophage, and smooth muscle cell content. Br Heart J 69(5): 377-381, 1993. PMID: 8518056. DOI: 10.1136/hrt.69.5.377 
18 Sfyroeras GS, Roussas N, Saleptsis VG, Argyriou C and Giannoukas AD: Association between periodontal disease and stroke. J Vasc Surg 55(4): 1178-8416, 2012. PMID: 22244863. DOI: $10.1016 /$ j.jvs.2011.10.008

19 Kinane DF and Lappin DF: Immune processes in periodontal disease: a review. Ann Periodontol 7(1): 62-71, 2002. PMID: 16013218. DOI: 10.1902/annals.2002.7.1.62

20 Mayr M, Metzler B, Kiechl S, Willeit J, Schett G, Xu Q and Wick G: Endothelial cytotoxicity mediated by serum antibodies to heat shock proteins of Escherichia coli and Chlamydia pneumoniae: immune reactions to heat shock proteins as a possible link between infection and atherosclerosis. Circulation 99(12): 1560-1566, 1999. PMID: 16013218. DOI: 10.1902/ annals.2002.7.1.62

21 Lafon A, Pereira B, Dufour T, Rigouby V, Giroud M, Béjot Y and Tubert-Jeannin S: Periodontal disease and stroke: a metaanalysis of cohort studies. Eur J Neurol 21(9): 1155-1161, 2014. PMID: 24712659. DOI: 10.1111/ene.12415

22 Noack B1, Genco RJ, Trevisan M, Grossi S, Zambon JJ and De Nardin E: Periodontal infections contribute to elevated systemic C-reactive protein level. J Periodontol 72(9): 1221-1227, 2001. PMID: 11577954. DOI: 10.1902/jop.2000.72.9.1221

23 Lockhart PB, Bolger AF, Papapanou PN, Osinbowale O, Trevisan M, Levison ME, Taubert KA, Newburger JW, Gornik HL, Gewitz MH, Wilson WR, Smith SC Jr, Baddour LM; American Heart Association Rheumatic Fever, Endocarditis, and Kawasaki Disease Committee of the Council on Cardiovascular Disease in the Young, Council on Epidemiology and Prevention, Council on Peripheral Vascular Disease and Council on Clinical Cardiology: Periodontal disease and atherosclerotic vascular disease: does the evidence support an independent association? A scientific statement from the American Heart Association. Circulation 125(20): 2520-2544, 2012. PMID: 22514251. DOI: 10.1161/CIR.0b013e31825719f3
24 Maekawa T, Tabeta K, Kajita-Okui K, Nakajima T and Yamazaki $\mathrm{K}$ : Increased expression of $\mathrm{C}$-reactive protein gene in inflamed gingival tissues could be derived from endothelial cells stimulated with interleukin-6. Arch Oral Biol 56(11): 1312-1318, 2011. PMID: 21550586. DOI: 10.1016/j.archoralbio.2011.04.010

$25 \mathrm{Lu}$ Q and Jin L: Human gingiva is another site of C-reactive protein formation. J Clin Periodontol 37(9): 789-796, 2010. PMID: 20666874. DOI: 10.1111/j.1600-051X.2010.01600.x

26 Kruck S, Hennenlotter J, Amend B, Geiger M, Filipova E, Neumann T, Stühler V, Schubert T, Todenhöfer T, Rausch S, Huettig F, Stenzl A and Bedke J: Chronic periodontitis does not impact serum levels of prostate-specific antigen. Anticancer Res 37(6): 3163-3167, 2017. PMID: 28551659. DOI: 10.21873/ anticanres. 11675

27 Lin F, Chen Y, Wan M, Chen W and Jia W: High-sensitivity Creactive protein as an indicator of ischemic stroke in patients with isolated acute vestibular syndrome: Retrospective observational study. Medicine (Baltimore) 98(48): e18097, 2019. PMID: 31770230. DOI: 10.1097/MD.0000000000018097

Received May 4, 2020

Revised June 2, 2020

Accepted June 9, 2020 